\section{Strategien gegen Pneumonien}

- Pneumonie ist die Haupttodesursache bei Kindern und betrifft keineswegs nur die Entwicklungsländer. Jährlich sterben daran über 1,5 Millionen Kinder weltweit - mehr als am HI-Virus, Malaria und Masern zusammen. Im Jahr 2008 waren es allein in Europa 20.727 Kinder im Alter unter fünf Jahren. Der „Global Action Plan for the Prevention and Control of Pneumonia“ (GAPP) der World Health Organization und die Überlebenskampagne „Every One“ der Kin-

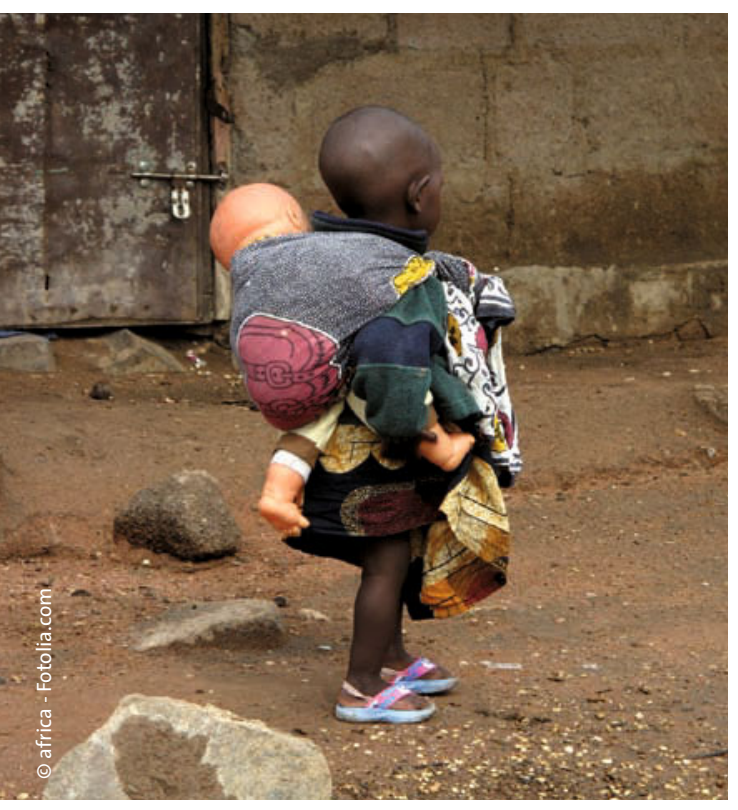

derrechtsorganisation Save the Children sollen dazu beitragen, das vierte Jahrtausendziel der Vereinten Nationen zu erreichen: die Sterblichkeit von Kindern unter fünf Jahren von 1990 bis 2015 um zwei Drittel zu senken. GlaxoSmithKline ist der Initiative „Save the Children“ und dem WHOAktionsplan zur Pneumonieprävention beigetreten.

„Bewährte preisgünstige Lösungen gegen das Sterben und Leiden von Kindern an Pneumonie sind Impfstoffe und Antibiotika“, sagte Dr. Tedbabe Degefie, Head of Health von Save the Children in Äthiopien. „Aber sie werden einfach nicht in ausreichendem Maßstab eingesetzt, um das Problem in den ärmsten Ländern der Welt anzugehen." Die Eltern sind außerdem selten darin geschult, die Symptome rechtzeitig zu erkennen, die medizinischen Versorgungszenten liegen oft weit entfernt und Antibiotikaresistenzen erschweren die Behandlung von bereits Erkrankten. Aussichtsreicher ist die Frühprävention: Dazu empfiehlt sich die Immunisierung mit Impfstoffen gegen Pertussis, Haemophilus influenzae Typ b und Pneumokokken.

Internationale Kampagnen sollen die Sterblichkeit von Kindern unter fünf Jahren bis 2015 um zwei Drittel senken - vor allem in Afrika.
Sie drängt gleichzeitig das Vorkommen der antibiotikaresistenten Erreger zurück. Weiter reduzieren angemessene Ernährung mit ergänzender Zinkgabe und - aus Gründen der Hygiene - ausschließliches Stillen während der ersten sechs Lebensmonate das Risiko, zu erkranken. Leichter gesagt als durchzusetzen: Die Mütter können entweder nicht stillen, weil sie ihre Kinder während des Broterwerbs bei Verwandten zurücklassen müssen, oder meiden es aus Angst vor einer HIV-Übertragung.

„Die Impfung ist eine der Schlüsselstrategien zur Pneumoniekontrolle", so das Fazit des GAPP-Vertreters Prof. Mathuram Santosham von der Johns Hopkins Bloomberg School of Public Health in Baltimore, USA. „Doch es besteht ein großer Unterschied, wo Kinder sterben und wo wirksame Impfstoffe routinemäßig eingesetzt werden. Das ist nicht akzeptabel!" Diese Lücke muss geschlossen werden, indem der Zugang zu lebensrettenden Impfstoffen für jene Kinder verbesser wird, die sie am nötigsten haben. GSK wird in den kommenden zehn Jahren bis zu 300 Millionen Dosen seines Pneumokokken-Impfstoffes Synflorix ${ }^{\circledR}$ zur Verfügung stellen.

we

Pressekonferenz „Childhood Pneumonia: Can we stop the suffering?”, im Rahmen des 26. International Pediatric Congress. Johannesburg (Südafrika), 4. August 2010. Veranstalter: GlaxoSmithKline, München

dass sie keinen Anästhesisten erfordert. Die Applikation erfolgt durch Einatmen des Patienten über ein bedarfsgesteuertes Ventil - durch die Tiefe des Atemzuges kann er die Analgesie beeinflussen. Da das Kind entsprechend mitarbeiten müsse, solle es nicht zu jung sein, so Weimann. Die häufigsten Nebenwirkungen seien Übelkeit bzw. Erbrechen, Schwindel, Benommenheit und Euphorie, führte er fort. Als mögliche Indikationen nannte Weimann kleine Wundversorgungen oder Metallentfernungen, Katheterisierungen, Punktionen, Verbandwechsel und Repositionen.

pe

Sitzung „Schmerztherapie bei Neugeborenen, Säuglingen und Kindern“, anlässlich des 127. Kongresses der Deutschen Gesellschaft für Chirurgie. Berlin, 23. April 2010. Veranstalter: Linde Gas Therapeutics, Unterschleißheim 